\title{
Bladder neck preservation during classic laparoscopic radical prostatectomy - point of technique and preliminary results
}

\author{
Piotr L Chłosta ${ }^{1-3}$, Tomasz Drewa ${ }^{3,4}$, Jarosław Jaskulski ${ }^{3}$, Jakub Dobruch ${ }^{1}$, John Varkarakis ${ }^{5}$, Andrzej Borówka ${ }^{1}$ \\ 1Department of Urology, The Medical University of Postgraduate Education, Warsaw, Poland \\ 2Faculty of Health, University of Humanities and Sciences, Kielce, Poland \\ 3Department of Urology, Institute of Oncology, Kielce, Poland \\ ${ }^{4}$ Department of Tissue Engineering, Nicolaus Copernicus University, Bydgoszcz, Poland \\ ${ }^{5}$ Department of Urology, Athens Medical University, Greece
}

Videosurgery and Other Miniinvasive Techniques 2012; 7 (2): 89-95 DOI: 10.5114/wiitm.2011.25981

\begin{abstract}
Introduction: Stress urinary incontinence after radical prostatectomy for prostate cancer organ-confined patients can significantly affect quality of life. The article presents a technique of bladder neck preservation, because it is believed that this point is one of many crucial points responsible for fast recovery of continence after laparoscopic radical prostatectomy $(L R P)$.

Material and methods: Laparoscopic radical prostatectomy with the intention of bladder neck preservation was performed in 194 patients of clinically organ-confined prostate cancer (cT2 INOMO). The working space was done by tissues-fingers dissections and insufflation of the cavity under full visual control, without the Gaur-balloon device. We insert two $10 \mathrm{~mm}$ trocars, three trocars of $5 \mathrm{~mm}$ and both $0^{\circ}$ and $30^{\circ}$ laparoscopes. The most important points of technique include: identification of landmarks of bladder neck and prostate base; dissection of muscle fibres of the very superficial bladder wall; mobilization of the posterior part of the urethra and simultaneous seminal vesicles release; neuro-vascular bundles preservation. This procedure resulted in a long bladder neck which can be easily anastomosed with the urethra. Tension-free and end-to-end (bladder neck-urethra) anastomosis are the results.

Results: In all cases radical prostatectomy was performed laparoscopically in the extraperitoneal space. There were no complications of bladder neck preservation during laparoscopic radical prostatectomy (LRP) apart from 22 cases with a large medium lobe. The mean time of operation was 150 min (110-210 min). The mean blood loss during LRP was $150 \mathrm{ml}$ (110-350 ml). Blood transfusion was not necessary. There were no postoperative complications. Mean hospitalization time was 5 days. Pathological result of the postoperative specimens was pT2a in 30\%, pT2b in 60\%, pT3a in 6\%, and pT3b in $4 \%$ of patients. In $7 \%$ of patients a positive surgical margin was affirmed, but the bladder neck was not affected in any case. Full continence after 3, 6, and 12 months was observed in 75\%, 85\%, and 92\% of analysed patients, respectively. Conclusions: Bladder neck preservation during $L R P$ is an effective, safe procedure that offers good functional results based on fast recovery of continence. Bladder neck preservation offers full tight anastomosis, especially in cases with no large median lobe of prostatic adenoma. Continence of patients who underwent bladder neck preservation was improved during short-term follow-up. Long-term results are still not conclusive. We think that this technique applied to laparoscopy will finally result in real progress of continence preservation after radical prostatectomy, but larger groups of patients have to be compared.
\end{abstract}

Key words: laparoscopic radical prostatectomy, stress urinary incontinence, bladder neck. 


\section{Introduction}

In most diseases, laparoscopic procedures, even complicated, offer better postoperative quality of life when compared to open procedures [1, 2]. Young surgeons are becoming more and more skilled in laparoscopy, so this type of approach is going to be used for emergency cases [3, 4]. On the other hand, we know that even difficult and complicated laparoscopic procedures are safe from an oncological point of view and they are equal to open oncological procedures $[5,6]$.

Incontinence after radical prostatectomy for early stage prostate cancer can significantly affect quality of life. Identification of crucial anatomical and functional points preoperatively would enable clinicians to preserve them, leading to a better postoperative outcome. Stress urinary incontinence is a well-recognized complication following radical prostatectomy. Fortunately, in the hands of experienced surgeons, the overwhelming majority of men ultimately regain urinary continence following the procedure, but it is almost impossible to predict the return of urinary continence after radical prostatectomy. Marsh and Lepor prepared a special scale for continence prediction after radical prostatectomy, but until now this tool is useless $[7,8]$. The important question is what to do with the bladder neck during radical laparoscopic prostatectomy [9].

The concept of bladder neck preservation was first presented during open retropubic radical prostatectomy $[10,11]$. The goal of the urological surgeon performing radical prostatectomy for prostate cancer is to eliminate the cancer and minimize the side effects associated with treatment. It seems that careful dissection of the prostate from the bladder can be

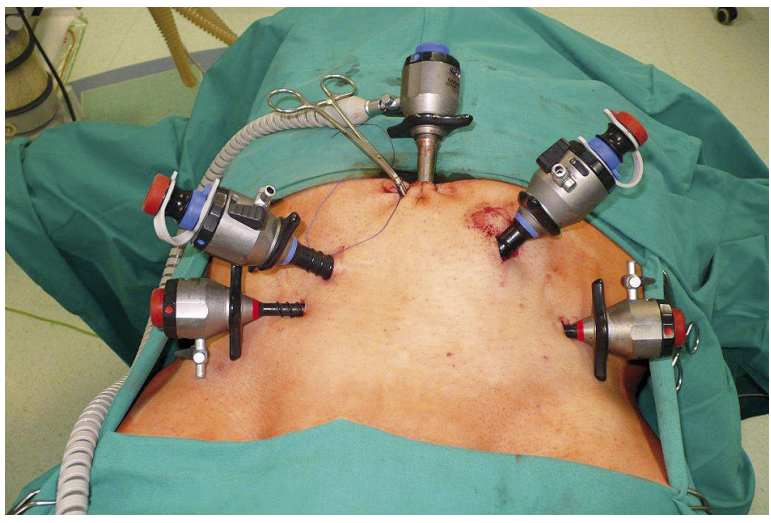

Figure 1. Port placement is similar to standard endoscopic retroperitoneal radical prostatectomy performed in such a manner as to preserve most of the circular fibres of the bladder neck. This so-called bladder-neck preservation technique appears to reduce the risk of an anastomotic stricture and accelerate the return of urinary continence [11]. The true urethra-to-urethra anastomosis is the goal of the technique [12]. A few years ago it was stated that all achievements of open procedures and new techniques can be used for developing uro-oncological laparoscopic surgery [9, 13-15].

\section{Aim}

In this paper we would like focus on the surgical technique regarding laparoscopic radical prostatectomy (LRP), but not on skills and surgeon volume. This is unquestioned; when laparoscopic radical prostatectomy is performed, the surgeon has to be skilled and high volume. We will present a technique of bladder neck preservation and preliminary results of continence recovery during the first year after LRP.

\section{Material and methods}

Laparoscopic radical prostatectomy with the intention of bladder neck preservation was performed in 194 patients of clinically organ-confined prostate cancer ( $\mathrm{CT} 2 \leq \mathrm{NOMO})$. We inserted two $10 \mathrm{~mm}$ trocars, three trocars of $5 \mathrm{~mm}$, and used both $0^{\circ}$ and $30^{\circ}$ laparoscopes (Figure 1). After creating the working space via an extraperitoneal approach through the retropubic space of the Retzius venous complex we ligated and then the bladder neck dissection was started. Two bipolar dissectors and cold scissors were used for preparing. Bladder neck preparation was started with careful and gentle dissection of muscle fibres of the very superficial bladder wall. Optical magnification can help to dissect muscle fibres around the urethra (Figure 2). The fibre pattern can be easily visualized, giving us the possibility to create spaces in both sites laterally of the preserving bladder neck (Figure 2). Then the posterior part of the urethra was mobilized and access to the Denonvilliers fascia was made, after retracting the urethra on the right side, the left vas deferens and seminal vesicle were fully visualized and mobilized. An analogical procedure was performed on the opposite side. This resulted in freeing both seminal vesicles on both sides of the urethra and the posterior surface of the prostate (Figure 3). The NVBs were identified. Then 
under full visual control a urethra was cut off by cold scissor dissection as long as possible to preserved muscle fibres running along the bladder neck and part of the prostatic urethra (Figure 4). Haemostasis was fully controlled during the whole procedure with low grade bipolar cautery. After prostate removal with two NVBs preservation (Figure 3) bladder neckurethra or even urethro-urethral anastomosis was performed by running suture using 6-12 stitches (Figures 5 and 6). Continence was defined as the patient needing no pads at all.

\section{Results}

In all cases radical prostatectomy was performed laparoscopically in the extraperitoneal space. In 22 cases $(11 \%)$ with a large median lobe of the prostatic adenoma, the bladder neck diameter became wider than expected, and it was necessary to adapt the bladder neck diameter to the urethra by knot sutures. Except this, there were no complications of bladder neck preservation during LRP. The mean time of operation was $150 \mathrm{~min}$ (110-210 $\mathrm{min})$. The mean blood loss during LRP was $150 \mathrm{ml}(110-350 \mathrm{ml})$. Blood transfusion was not necessary in any case of LRP. There were no postoperative complications. Surgical outcome based on back to vital activity/back to normal diet and hospitalization time was 2 and 5 (4-7) days respectively. The median catheter time was 7 (5-9) days. Pathological result of the postoperative specimens was pT2a in 58 patients (30\%), pT2b in 117

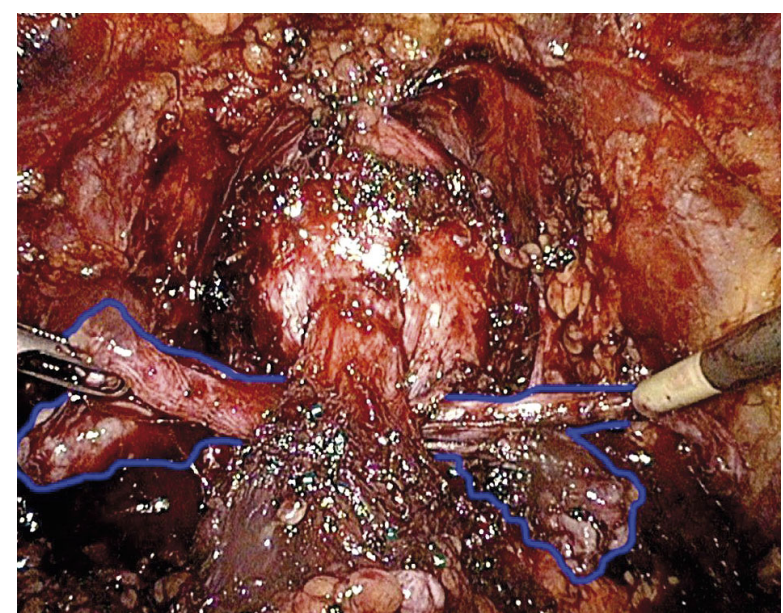

Figure 3. Posterior part of the urethra was mobilized, facilitating dissection of the seminal vesicles (marked with blue line)

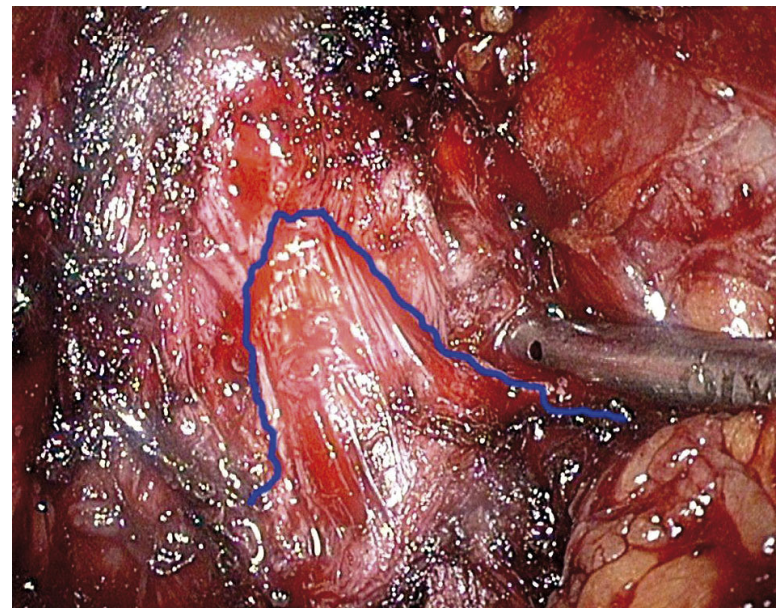

Figure 2. Dissection of muscle fibres of the very superficial bladder wall. The border of fibres pattern can be easily visualized (marked with blue line)

(60\%), pT3a in 12 (6\%), and pT3b in 7 (4\%) patients (Table I). In 14 patients (7\%) a positive surgical margin was affirmed, but the bladder neck was not affected. Analysis of fast continence recovery was performed on 153 eligible patients. The continence rates are presented in Table II. Our results were compared to other series of open radical prostatectomy, extraperitoneal laparoscopic radical prostatectomy, and robotic-assisted laparoscopic radical prostatectomy (Table II) [14, 16-18]. It can be easily noticed that short term continence (1-4 months) favours bladder neck preservation (Table II). After one year of follow-

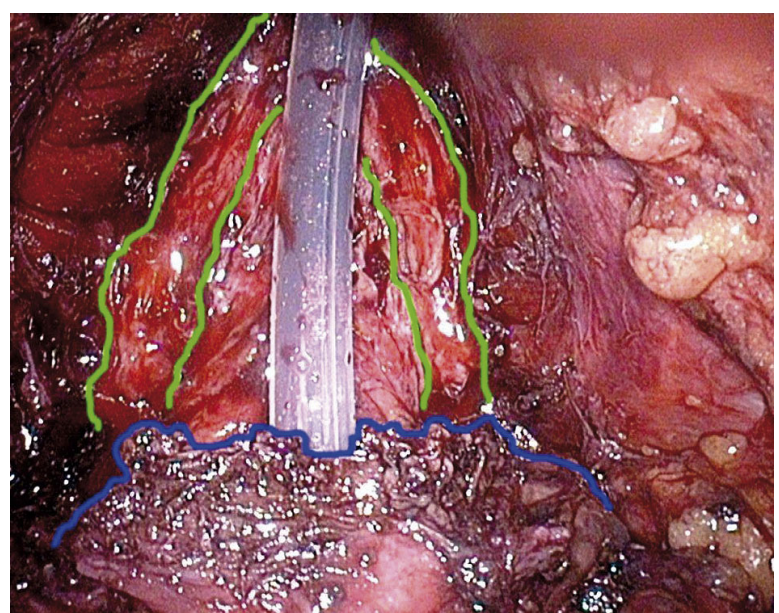

Figure 4. Neuro-vascular bundles can be easily noticed (marked with green). The preserved bladder neck (blue) is now dissected with the inserting catheter 


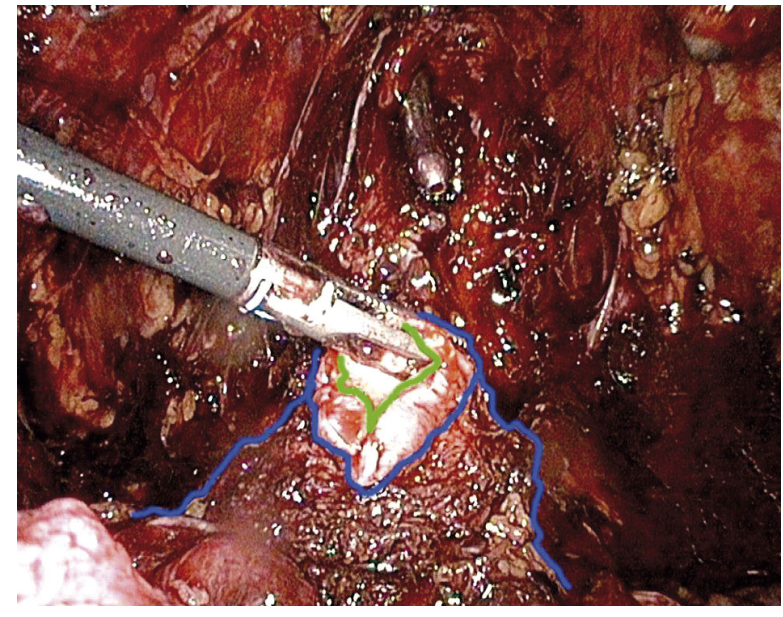

Figure 5. Long bladder neck (blue line) is ready to perform anastomosis. The bladder lumen is marked with a green line

up the continence rate was similar (81-94\%) in all trials, regardless of whether modification was performed (Table II).

There are some advantages of the proposed LRP modification. One of them is the reduced number of sutures with full tightness of anastomosis. This tech-

Table I. Table presents dispersion of pathologic staging in patients who undergone LRP with bladder neck preservation

\begin{tabular}{|lc|}
\hline Stage & Bladder neck preservation LRP group (194 pts) \\
\hline T2a & $58(30 \%)$ \\
\hline T2b & $117(60 \%)$ \\
\hline T3a & $12(6 \%)$ \\
\hline T3b & $7(4 \%)$ \\
\hline
\end{tabular}

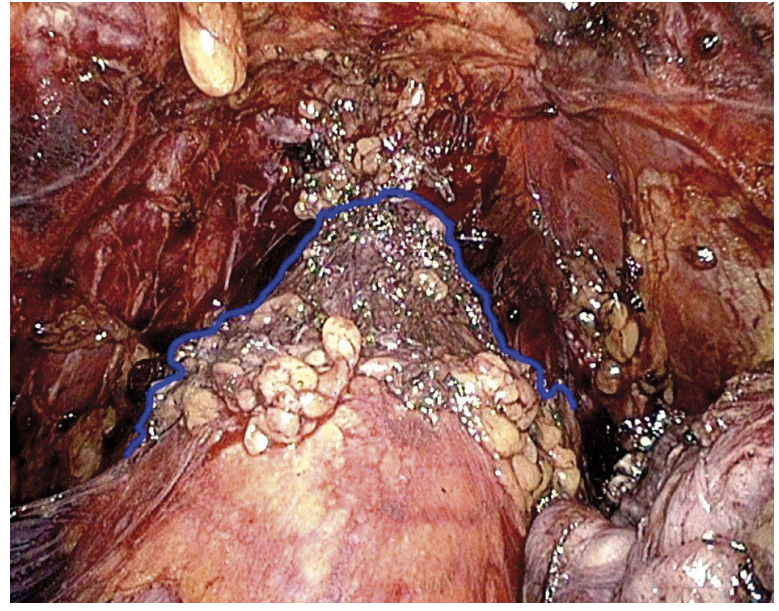

Figure 6. Cone shape of preserved bladder neck (blue) and tension-free end-to-end anastomosis

nique offered close, tight adherence, resembling the natural one, between created urethral parts; anastomosis end-to-end without tension was achieved serving as a landmark for the incision point of the bladder neck dissection; visualization of the contour of the urethral catheter balloon as the empty bladder caves in to form a concave contour bilaterally before and after prostate removal (Figure 6). The spherical contour of the Foley catheter balloon may be more difficult to appreciate in men with a greater amount of perivesical adipose tissue; however, we do not use the position of the balloon as a reference point to perform the bladder neck dissection. Second, at the distal termination of the elevated bladder ridge, the bipolar current is used to control bleeding as sharp dissection is performed with the cold scissors. Avoiding the use of monopolar cautery lessens the amount

Table II. Our results (the first 3 columns) were compared to other series: A - Arroua et al., 2008; B - Bollens et al., 2000; C - Freire et al., 2009; D - Stozenburg et al., 2010. The short term results are bold and underlined. Results of bladder neck preservation are marked with grey, patients who underwent standard procedures without BNP can be found in white columns

\begin{tabular}{|c|c|c|c|c|c|c|c|c|c|c|c|c|c|c|c|c|c|c|c|c|}
\hline \multirow[b]{2}{*}{ Follow up [months] } & \multicolumn{3}{|c|}{$\begin{array}{l}\text { LRP } \\
\text { BNP }\end{array}$} & \multicolumn{3}{|c|}{$\begin{array}{c}\text { ORP } \\
\text { BNP, A }\end{array}$} & \multicolumn{2}{|c|}{$\begin{array}{c}\text { LRP } \\
B\end{array}$} & \multicolumn{3}{|c|}{$\begin{array}{l}\text { RALP } \\
\text { BNP, C }\end{array}$} & \multicolumn{3}{|c|}{$\begin{array}{c}\text { RALP } \\
\text { C }\end{array}$} & \multicolumn{3}{|c|}{$\begin{array}{c}\text { LRP } \\
\text { BNP, D }\end{array}$} & \multicolumn{3}{|c|}{$\begin{array}{c}\text { LRP } \\
D\end{array}$} \\
\hline & 3 & 6 & 12 & 1 & 6 & 12 & 3 & 6 & 4 & 12 & 24 & 4 & 12 & 24 & 3 & 6 & 12 & 3 & 6 & 12 \\
\hline $\mathrm{N}^{\circ}$ of analyzed patients & 153 & 117 & 52 & 180 & 180 & 180 & 50 & 50 & 348 & 348 & 348 & 271 & 271 & 271 & 150 & 150 & 150 & 90 & 90 & 90 \\
\hline Continence (no pads) rate [\%] & $\underline{75}$ & 85 & 92 & $\underline{71}$ & 85 & 89 & $\underline{39}$ & 85 & $\underline{66}$ & 86 & 100 & $\underline{27}$ & 81 & 96 & $\underline{73}$ & 87 & 94 & $\underline{61}$ & 81 & 92 \\
\hline
\end{tabular}

$B N P$ - bladder neck preservation, RALP - robotic-assisted laparoscopic radical prostatectomy, $L R P$ - laparoscopic radical prostatectomy, ORP - open radical prostatectomy 
of tissue charring, thus preserving visualization of the native anatomy that allows for identification of bladder muscle fibres, critical for defining the natural tissue plane of the vesicoprostatic junction. Once the linear fibres of the bladder neck transitioning to the prostatic urethra are identified in the midline (Figure 2), we find the cleavage plane using a combination of sharp and blunt dissection to tease bladder muscle fibres away from the prostate, anatomically preserving a funnelled bladder neck (Figure 3).

\section{Discussion}

Eastham and colleagues stated that while the risk of urinary incontinence after radical prostatectomy is related to the uncontrollable factor of patient age, it is also sensitive to the surgical technique used [19]. It should be emphasized that many other preoperative risk factors affecting continence exist, e.g. baseline incontinence, diabetes, and previous TURP [20]. Despite several risk factors being found, a consensus on this topic was not achieved [15].

Continence evaluation usually differs for each study. Comparability is difficult because operative technique, group's features and mean of functional evaluation were different from study to study. We have found several studies comparable with our data, with similar definitions of incontinence, periods of observations, and applied technique. All these data are presented in one table (Table II). Based on this analysis we can note that continence of patients who underwent bladder neck preservation was improved during short-term follow-up but one-year results are still not conclusive.

Selli et al. found that bladder neck preservation during open radical prostatectomy does not improve the long-term results of urinary continence but does contribute substantially to its earlier recovery, thus improving the quality of life [21]. Azuma et al. proposed six crucial points important for postoperative urinary continence after laparoscopic radical prostatectomy; one of them is preservation of the bladder neck. Others include minimal distal incision of the endopelvic fascia; bilateral nerve-sparing surgery; preservation of the posterior (membranous) urethra; suturing of the posterior aspect of the rhabdosphincter, the remaining portion of the Denonvilliers fascia, and the bladder neck (restoration of the Denonvilliers fascia) [22]. Some of them are very sophisticated and questionable. Puboprostatic ligaments preservation has been proposed as a method to accelerate continence recovery after radical prostatectomy. However, these ligaments present anatomical continuity with the bladder, and there must be interruption at some point during the procedure. The preservation of puboprostatic ligaments during LRP is technically feasible. It leads towards absolute preservation of the periprostatic anatomy that may enhance early functional outcomes, but further studies are needed to confirm this hypothesis [23].

It seems that bladder neck preservation is rather easy to perform. This procedure can be repeated in almost all LRP. Bladder neck preservation may aid in an earlier return of continence following radical prostatectomy [24]. It does not appear to compromise the removal of the cancer, but preliminary observations related to this technique were inconclusive. Preservation of the bladder neck does not have a general impact on return of urinary control but may be associated with a lower risk of vesical neck contracture. Our results partially confirm this, but detailed analysis was not performed due to the relatively short follow-up and small group of patients (53) at the point of 12 months.

Several studies showed that preservation of the bladder neck did not compromise cancer control with some exceptions [10-12]. Marcovich et al. suggested that bladder neck preservation modification of radical prostatectomy should not be used for stages higher then pT3a, as it can be associated with an increased rate of positive surgical margins [25]. An analysis of 676 consecutive prostatectomies revealed that $4.3 \%$ of the men had tumour touching the inked bladder neck margin [11]. Moreover, a randomized trial showed no statistically significant differences between groups in early or late urinary continence rates between groups with spared bladder neck and standard open radical prostatectomy procedure [26]. On the other hand, Bianco et al. performed a huge analysis on 555 patients who had undergone open radical prostatectomy and showed that anatomical preservation of the bladder neck does not increase the percentage of positive margins at this anatomical location and does not compromise disease-free survival [27]. Novel laparoscopic and robotic-assisted series have confirmed Bianco's observations $[17,18]$. Our data from 194 patients revealed $7 \%$ positive margins but none of them were located within the bladder neck.

Quite a novel study of Freire and colleagues analysed 619 consecutive robotic-assisted laparo- 
scopic radical prostatectomies and found that despite a learning curve with bladder neck dissection as a challenging step for newcomers, bladder neck preservation can be a reproducible technique. They stated that bladder neck preservation versus standard technique is associated with quicker recovery of urinary function and similar cancer control [17]. Stolzenburg et al. compared retrospectively 150 patients who underwent bladder neck preservation during LRP and 90 patients treated with bladder neck resection. The authors found that bladder neck preservation has an impact on postoperative early continence of patients undergoing LRP. Continence of patients who underwent bladder neck preservation was improved after catheter removal and at the 3-month follow-up in comparison to those without bladder neck preservation. Oncological results were similar in both groups analysed by Stolzenburg et al. [18]. It can be speculated that bladder neck preservation will result in increase of the total number of continent patients after LRP, but larger groups have to be compared. We think that this technique applied to laparoscopic and robotic-assisted radical prostatectomy will finally result in real progress of continence preservation after radical prostatectomy.

\section{Conclusions}

Bladder neck preservation during LRP is an effective, safe procedure that offers good functional results based on fast continence recovery. Bladder neck preservation facilitates full tight anastomosis, especially in cases with no large median lobe of prostatic adenoma.

\section{References}

1. Kaska Ł, Śledziński Z, Kobiela J, et al. Comparision of quality of life after laparoscopic and open procedures. Videosurgery and Other Miniinvasive Techniques 2006; 2: 77-86.

2. Rembiasz K, Bobrzyński A, Budzyński A, et al. Analysis of complications of laparoscopic management of abdominal diseases related to extended indications. Videosurgery and Other Miniinvasive Techniques 2010; 5: 53-9.

3. Budziński R, Michalik M, Frask A. Education in laparoscopic surgery. Videosurgery and Other Miniinvasive Techniques 2008; 3 : 22-9.

4. Strzałka M, Bobrzyński A, Budzyński A, et al. Open or laparoscopic appendectomy? Videosurgery and Other Miniinvasive Techniques 2009; 4: 110-4.

5. Frask A, Michalik M, Orłowski M. Port-side implantations after minimal invasive surgery - etiology and protection. Videosurgery and Other Miniinvasive Techniques 2008; 1: 17-21.

6. Chlosta P, Drewa T, Siekiera J, et al. Lymph node dissection during laparoscopic (LRC) and open (ORC) radical cystectomy due to muscle invasive bladder urothelial cancer (pT2-3, TCC). Videosurgery and Other Miniinvasive Techniques (e-pub 2011, ahead of print).

7. Marsh DW, Lepor H. Predicting continence following radical prostatectomy. Curr Urol Rep 2001; 2: 248-52.

8. Twiss C, Martin S, Shore R, Lepor H. A continence index predicts the early return of urinary continence after radical retropubic prostatectomy. I Urol 2000; 164: 1241-7.

9. Goeman L, Salomon L, Hoznek A, et al. Radical laparoscopic prostatectomy: should we do bladder neck preservation or a reconstruction? Curr Urol Rep 2006; 7: 93-5.

10. Licht MR, Klein EA, Tuason L, Levin H. Impact of bladder neck preservation during radical prostatectomy on continence and cancer control. Urology 1994; 44: 883-7.

11. Gomez CA, Soloway MS, Civantos F, Hachiya T. Bladder neck preservation and its impact on positive surgical margins during radical prostatectomy. Urology 1993; 42: 689-93.

12. Gaker DL, Gaker LB, Stewart JF, Gillenwater JY. Radical prostatectomy with preservation of urinary continence. J Urol 1996; 156: 445-9.

13. Borkowski T, Leszczyński D, Borkowski A. Application of a stapling device for hemostasis of Santorini venous complex during radical prostatectomy - preliminary results. Videosurgery and Other Miniinvasive Techniques 2006; 4: 175-9.

14. Bollens R, Vanden Bossche $M$, Roumeguere $T$ et al. Extraperitoneal laparoscopic radical prostatectomy. Results after 50 cases. Urology 2000; 55: 904-8.

15. Simonin O, Savoie PH, Serment G, et al. Urinary incontinence following open prostatectomy or laparoscopy for local prostate cancer. A review of relevant literature. Prog Urol 2010; 20 : 239-50.

16. Arroua F, Toledano H, Gaillet S, et al. Radical prostatectomy with bladder neck preservation: surgical margins and urinary continence. Prog Urol 2008; 18: 304-10.

17. Freire MP, Weinberg AC, Lei $Y$, et al. Anatomic bladder neck preservation during robotic-assisted laparoscopic radical prostatectomy: description of technique and outcomes. Eur Urol 2009; 56: 972-80.

18. Stolzenburg JU, Kallidonis P, Hicks J, et al. Effect of bladder neck preservation during endoscopic extraperitoneal radical prostatectomy on urinary continence. Urol Int 2010; 85: 135-8.

19. Eastham JA, Kattan MW, Rogers E, et al. Risk factors for urinary incontinence after radical prostatectomy. J Urol 1996; 156: 1707-13.

20. Moore KN, Truong V, Estey E, Voaklander DC. Urinary incontinence after radical prostatectomy: can men at risk be identified preoperatively? J Wound Ostomy Continence Nurs 2007; 34: 270-9.

21. Selli C, De Antoni P, Moro U, et al. Role of bladder neck preservation in urinary continence following radical retropubic prostatectomy. Scand J Urol Nephrol 2004; 38: 32-7.

22. Azuma H, Ibuki N, Inamoto T, et al. Laparoscopic radical prostatectomy: six key points of operative skill for achieving better urinary continence. Nippon Hinyokika Gakkai Zasshi 2010; 101: 1-12.

23. Asimakopoulos AD, Annino F, D'Orazio A, et al. Complete periprostatic anatomy preservation during robot-assisted laparoscopic radical prostatectomy (RALP): the new pubovesical complexsparing technique. Eur Urol 2010; 58: 407-17. 
24. Braslis KG, Petsch M, Lim A, et al. Bladder neck preservation following radical prostatectomy: continence and margins. Eur Urol 1995; 28: 202-8.

25. Marcovich R, Wojno KJ, Wei JT, et al. Bladder neck-sparing modification of radical prostatectomy adversely affects surgical margins in pathologic T3a prostate cancer. Eur Urol 2003; 43: 461-6.

26. Srougi M, Nesrallah LJ, Kauffmann JR, et al. Urinary continence and pathological outcome after bladder neck preservation during radical retropubic prostatectomy: a randomized prospective trial. J Urol 2001; 165: 815-8.

27. Bianco FJ, Grignon DJ, Sakr WA, et al. Radical prostatectomy with bladder neck preservation: impact of a positive margin. Eur Urol 2001; 40: 65-9. 